\title{
EDITORIAL
}

\section{Denver X-ray Conference - A Review of 2015 and Looking Forward to 2016}

During the summer of 2015, the 64th Annual Denver X-ray Conference (DXC) was held in Westminster, Colorado. In addition to sessions dedicated to diffraction and fluorescence applications, this DXC was also a joint meeting with the 16th International Conference on Total Reflection X-ray Fluorescence Analysis and Related Methods (TXRF 2015). Joint meetings create a synergy amongst attendees, allowing for interactions that not only enhance the total conference experience, but also result in the advent of collaborative contacts that have lasting benefits for attendees. One aspect that has made the DXC meetings so successful are the workshops that are open to all attendees. This year, 15 half-day DXC and a full day of TXRF workshops were presented benefitting beginners and experts alike. Included with this issue of Powder Diffraction Journal is a full summary of the 2015 meeting.

New to DXC in 2016 will be the location of the meeting. For the first time it will be in Rosemont, Illinois, near Chicago, the dates being 1-5 August, 2016. (http://www.dxcicdd.com/). This location is close to one of the premier research facilities in the world, Argonne National Laboratories, including the Advanced Photon Source. Planning for the upcoming 65th Annual DXC is taking shape, and expect workshops and sessions emphasizing the use of synchrotron radiation to be a significant part of meeting. Students should take special note as financial support through Robert L. Snyder scholarships (http://www.icdd.com/resources/awards/snyder.htm) will be available. Applications are reviewed on a competitive basis. Grants are awarded in the amount of US\$500 for undergraduate or graduate students living within the USA, and US\$1000 for those living outside of the USA. Snyder award recipients also receive free registration to attend $\mathrm{DXC}$.

2016 will also be a year of anniversaries; 100 years of X-ray powder diffraction, 75 years of ASTM/JCPDS/ICDD and the Powder Diffraction File ${ }^{\mathrm{TM}}$ (PDF), and 30 years of Powder Diffraction Journal. Join us at the 2016 DXC meeting for the workshops, sessions, and the celebration.

Tom Blanton

ICDD Principal Scientist 